\title{
Prognostic role of Gli1 expression in breast cancer: a meta- analysis
}

\author{
Bilan Wang ${ }^{1,2,3}$, Ting $\mathrm{Yu}^{4}$, Yuzhu Hu${ }^{4}$, Mengmeng Xiang ${ }^{4}$, Haoning Peng ${ }^{4}$, Yunzhu \\ Lin $^{1,2,3}$, Lu Han ${ }^{1,2,3}$ and Lingli Zhang ${ }^{1,2,3}$ \\ ${ }^{1}$ Department of Pharmacy, West China Second University Hospital, Sichuan University, Chengdu, 610041, PR China \\ ${ }^{2}$ Evidence-Based Pharmacy Center, West China Second University Hospital, Sichuan University, Chengdu, 610041, PR China \\ ${ }^{3}$ Key Laboratory of Birth Defects and Related Diseases of Women and Children, Ministry of Education, West China Second \\ University Hospital, Sichuan University, Chengdu, 610041, PR China \\ ${ }^{4}$ Cancer Center, West China Hospital, West China Medical School, Sichuan University and Collaborative Innovation Center, \\ Chengdu, 610041, PR China
}

Correspondence to: Bilan Wang, email: tt173217@163.com

Lingli Zhang, email: zhlingli@sina.com

Keywords: Gli1, breast cancer, prognosis

Received: May 31, $2017 \quad$ Accepted: June 20, $2017 \quad$ Published: July 07, 2017

Copyright: Wang et al. This is an open-access article distributed under the terms of the Creative Commons Attribution License 3.0 (CC BY 3.0), which permits unrestricted use, distribution, and reproduction in any medium, provided the original author and source are credited.

\section{ABSTRACT}

Glioma-associated oncogene 1 (Gli1) is a critical transcriptional factor of Sonic hedgehog pathway which has been proved to participate in the initiation and progression of tumor in mammalians. However, its clinical value in breast cancer remains unknown. Thus, a meta-analysis was performed to clarify the association of Gli1 over-expression, clinic-pathological characteristics, molecular subtypes and prognosis in breast cancer. According to included criteria, 13 eligible studies containing 2816 patients all around the world were selected in this study. Our results indicated no significant association of Gli1 expression and histological grade $(R R=1.20,95 \% \mathrm{CI}:[0.98,1.47])$, $\mathrm{T}$ stage $(R R=1.05,95 \% C I:[0.87,1.27])$, clinical stage $(R R=1.04,95 \% C I:[0.93,1.18])$ and lymph node metastasis ( $R R=1.12,95 \% \mathrm{CI}$ : $[0.92,1.37])$. In addition, pooled $R R$ showed no correlation of Gli1 expression and progesterone receptor (PR) $(R R=0.92$, 95\% CI: $[0.70,1.21])$, estrogen receptor $(E R)(R R=1.03,95 \% C I:[0.74,1.42])$, human epidermal growth factor receptor $2(H E R-2)(R R=1.12,95 \%$ CI: $[0.90,1.39])$. Nonetheless, up-regulated Gli1 expression predicts shorter disease-free survival (DFS) $(H R=1.38,95 \%$ CI: $[1.05,1.81])$, 3-year survival $(H R=1.74,95 \%$ CI: $[1.28,2.36])$, 5 -year survival $(H R=2.04,95 \% C I:[1.62,2.57])$ and overall survival $(O S)(H R=2.05$, 95\% CI: [1.60, 2.64]). In conclusion, over-expression of Gli1 tends to progressive stages and is related to unfavorable prognosis of breast cancer, which may become a potential prognosis indicator and therapy target in breast cancer.

\section{INTRODUCTION}

Worldwide, morbidity of breast cancer has been increased to 1.7 million in 2012. For females, breast cancer has the highest mortality rate among all cancer types, accounting for $15 \%$ of all cancer deaths [1]. In China, its age-standardized incidence rate has been increasing significantly in the last decade [2]. The general therapeutic strategies are based on locoregional tumor load, molecular subtype and patients' preferences in early breast cancer [3]. In metastatic breast cancer, principles of systemic therapy mainly include chemotherapy, targeted therapy and endocrine therapy [4]. Breast cancer biology plays an important role in the selection of therapeutic plan [5]. Moreover, progesterone receptor (PR), estrogen receptor (ER) and human epidermal growth factor receptor 2 (HER-2) are the only clinically relevant biomarkers and verified therapeutic targets in metastatic breast cancer. However, potential heterogeneity between primary tumor and metastasis, even between metastases, find a potential therapeutic target becomes particularly important, especially in triple-negative metastatic breast 
cancer $[6,7]$. Therefore, more effective therapeutic strategies of breast cancer underlie a better understanding of novel molecular targets and signaling pathways that are closely related to the clinic-pathological prognostic factors of breast cancer.

Sonic hedgehog (Shh) signaling pathway, one of the components of the hedgehog (hh) pathway, was originally known to play an important role in embryonic development, cell maturation including differentiation, proliferation and maintenance of tissue polarity [7-9]. Recent studies have demonstrated that the SHH pathway was also involved in the invasion and metastasis process of solid tumor via its interaction with cancer stem cells (CSC) $[10,11]$ This signaling pathway is initiated with the secretion of Shh glycoprotein, activating the transmembrane protein Patched 1 (PTCH1) by binding with it. The activation of the PTCH1 relieves the inhibition of the Smoothened (Smo), thereby leading to the activation of Glioma-associated oncogene 1 transcription factors [7]. As the final effective factor of the Shh pathway, Gli1, which is considered as a valuable maker of Shh pathway activation, has been reported to be involved in cell selfrenewal, cell proliferation, survival, invasion, angiogenesis and epithelial-mesenchymal transition through regulating expressions of certain genes $[12,13]$. Thus, abnormal cell development and even oncogenesis tend to happen when Gli1 is dysregulated. Several types of carcinoma have been reported to have aberrant activation of Gli1, including hepatocellular carcinoma, gastric cancer, lung cancer, breast cancer and basal cell carcinoma, indicating the dysregulation of Gli1 may contribute to malignant biological behavior [14-16]. Clinical studies have also demonstrated that the expression of Gli1 can be utilized as a potential maker and imply poor prognosis in lung squamous cell carcinoma, basal cell carcinoma, head and neck squamous carcinoma which indicting the potential prognostic value of Gli1 $[17,18]$. However, the functional and prognostic significance of Gli1 in breast cancer still remains unclear. Some studies have indicated that overexpression of Gli1 predicted poor outcome of breast cancer with higher tumor stage and increased number of tumor-positive axillar lymph nodes [19, 20]. While other study showed no significant correlation between expression level of Gli1 and cancer-specific survival in ER $\alpha$-positive breast cancer [20].

Hence, to clarify the association of Gli1 overexpression and clinicopathological features, molecular subtypes, and clinical outcomes in breast cancer, a metaanalysis was performed via acquired available published data.

\section{RESULT}

\section{Literature selection and characteristics}

We recruited 706 eligible studies from Pubmed/ $\operatorname{MEDLINE}(n=387)$ and EMBASE $(n=319)$ according to the literature retrieval method mentioned above. Two independent investigators (Bilan Wang and Ting Yu) went through title and abstract of these articles and excluded 535 unrelated citations. Meanwhile, 134 studies were removed from scope because of duplicate data. The remaining 37 candidate studies were reviewed carefully by full text. Among them 12 were conference abstracts and 10 were not exploitable for survival data or clinicpathological data associated with Gli1. In addition, 1 nonEnglish (Chinese) and 1 review article were excluded as well. Ultimately, our study included 13 articles for further data extraction and analysis (Figure 1). The 13 included studies [8, 19, 20, 23-32] were published between 2009 and 2016. A total number of 2816 patients from Australia, America, Sweden, China, Korea and Germany were investigated and sample size varied from 83 to 334 . All studies performed immunohistochemistry (IHC) to evaluate the expression of Gli1. In data analysis, 6 studies $[8,19,25,29,31,32]$ provided information for overall survival (OS), 4 studies [8, 25, 31, 32] provided disease free survival (DFS), 1 study [20] provided cause specific survival (CSS), 1 study [23] provided distal metastasis free survival (DMFS), 1 study [27] for regression free survival (RFS), 1 study [28] for event free survival (EFS). Detailed Characteristics were demonstrated in Table1, and main outcomes presented in this meta-analysis were summarized in Table 2.

\section{Gli1 expression and clinic-pathological parameters}

We performed pooled analysis on correlations between Gli1 expression and a series of clinic-pathological parameters (Figure 2). Firstly, we summarized data about histological grade and Gli1 expression from 7 studies $[19,24,26,28,30-32]$ and discovered that histological grade was not correlated with Glil high expression $(\mathrm{RR}=1.20,95 \% \mathrm{CI}:[0.98,1.47])$. Next, data on T stage and Gli1 expression from another 7 studies [19, 24, 26-28, 30, 32] were calculated and we found that there is no significant association between $\mathrm{T}$ stage and Gli1 expression $(\mathrm{RR}=1.05,95 \% \mathrm{CI}$ : $[0.87,1.27])$. Then, we investigated 3 studies [24, 26, 27] finding no obvious correlation between clinical stage and Gli1 high expression $(\mathrm{RR}=1.04,95 \% \mathrm{CI}:[0.83,1.18])$. Finally, lymph node metastasis was not associated with Gi1 expression based on information from 8 studies [19, 24, 26-28, 30-32] $(\mathrm{RR}=1.12,95 \% \mathrm{CI}:[0.92,1.37])$. For histological grade, $\mathrm{T}$ stage and lymph node metastasis parameter analysis, random-effects model was utilized because of obvious heterogeneities $\left(I^{2}=62.9 \%, I^{2}=52.1 \%, I^{2}=75.9 \%\right.$, respectively), while fixed-effects model was applied in clinical stage parameter analysis $\left(I^{2}=0.0 \%\right)$. To sum up, our study revealed Gli1 expression was not associated with histological grade, T stage, clinical stage or lymph node metastasis in breast cancer. 


\section{Gli1 expression and immunohistochemical parameters}

Considering breast cancer is a typical hormonerelated cancer, we performed pooled analysis on correlations between Gli1 expression and three specific immunohistochemical parameters (PR, ER, HER-2) in breast cancer patients (Figure 3). Our results reported there was no significant association between PR [19, 26, 27, 32] $(\mathrm{RR}=0.92,95 \% \mathrm{CI}:[0.70,1.21]), \mathrm{ER}[19,26,27,29,32]$ $(\mathrm{RR}=1.03,95 \% \mathrm{CI}:[0.74,1.42])$, HER-2 $[26,27,32]$ $(\mathrm{RR}=1.12,95 \% \mathrm{CI}:[0.90,1.39])$ expression and Gli1 expression. Random-effects model was applied in all analysis of correlation between PR, ER, HER-2 and Glil for obvious heterogeneities $\left(I^{2}=83.8 \%, I^{2}=88.0 \%\right.$, $I^{2}=55.4 \%$, respectively).

\section{Gli1 expression and breast cancer survival outcome}

Survival outcomes of breast cancer with high and low Gli1 expression from 6 studies were extracted and analyzed (Figure 4). Result showed Gli1 over-expression was correlated with shorter DFS in breast cancer patients $(\mathrm{HR}=1.38,95 \% \mathrm{CI}:[1.05,1.81])$. Moreover, both 3-year survival $(\mathrm{HR}=1.74,95 \% \mathrm{CI}:[1.28,2.36])$ and 5 -year survival $(\mathrm{HR}=2.04,95 \% \mathrm{CI}$ : $[1.62,2.57])$ were worse in high Gli1 expression breast cancer cohort compared with low Gli1 expression cohort. Consistently, there was also significant association between Gli1 over-expression and poor OS (HR $=2.05,95 \% \mathrm{CI}$ : [1.60, 2.64]) of breast cancer patients. Random-effects model was utilized in this analysis of DFS for obvious heterogeneity $\left(I^{2}=54.2 \%\right)$. In all, our results indicated up-regulated expression of Gli1 was associated with poor survival outcomes involving DFS, 3-year survival, 5-year survival and OS.

\section{Publication bias}

Both Begg's funnel plot and Egger's test were performed to evaluate the publication bias in all studies assessing histological grade, $\mathrm{T}$ stage, clinical stage, lymph node metastasis, DFS, 3-year and 5-year survival and OS, respectively (Figure 5). Neither Begg's funnel plot nor Egger's test demonstrated any evidence of statistically significant asymmetry in the meta-analysis of

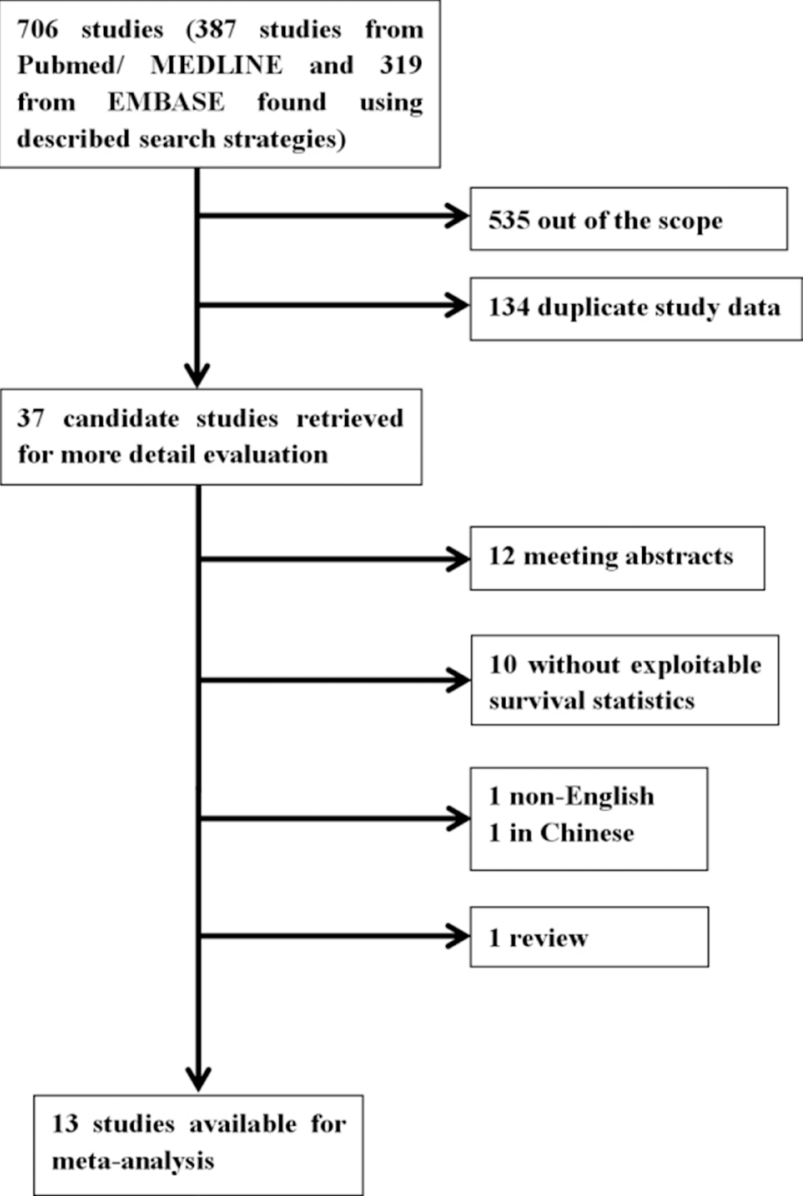

Figure 1: Flow chart of the literature search of this meta-analysis. 
Table 1: Characteristics of all identified studies

\begin{tabular}{|c|c|c|c|c|c|c|c|c|c|c|c|c|c|c|}
\hline & $\begin{array}{l}\text { first author } \\
\text { (ref) }\end{array}$ & year & country & $\begin{array}{c}\text { number } \\
\text { (F) }\end{array}$ & $\begin{array}{l}\text { pathological } \\
\text { classification }\end{array}$ & $\begin{array}{c}\text { molecular } \\
\text { classification }\end{array}$ & $\begin{array}{l}\text { Surgery } \\
(\%)\end{array}$ & method & $\begin{array}{c}\text { antibody } \\
\text { source }\end{array}$ & $\begin{array}{l}\text { definition of } \\
\text { Gil }+ \text { positive }\end{array}$ & $\begin{array}{l}\text { expression } \\
\text { rate (\%) }\end{array}$ & $\begin{array}{l}\text { median } \\
\text { follow-up } \\
\text { (m) }\end{array}$ & $\begin{array}{l}\text { survival } \\
\text { analysis }\end{array}$ & $\begin{array}{l}\text { NOS } \\
\text { score }\end{array}$ \\
\hline 1 & $\begin{array}{l}\text { Sandra A. } \\
\text { O'Toole }\end{array}$ & 2011 & Australia & 282 & $\begin{array}{l}\text { invasive ductal } \\
\text { carcinoma/ } \\
\text { ductal carcinoma } \\
\text { in situ }\end{array}$ & NR & NR & $\mathrm{IHC}$ & Santa Cruz & $\geq 20 \%$ & $31 \%$ & NR & os & 7 \\
\hline 2 & Lusheng Xu & 2010 & USA & 171 & $\begin{array}{l}\text { infiltrating ductal } \\
\text { carcinomas }\end{array}$ & NR & NR & $\mathrm{IHC}$ & Santa Cruz & $>2 \%$ & $32.37 \%$ & 93.6 & CSS & 7 \\
\hline 3 & Yumei Diao & 2016 & Sweden & 126 & NR & ER $\alpha$-positive & NR & NR & $\mathrm{NR}$ & NR & NR & NR & DMFS & 6 \\
\hline 4 & Shiwei Liu & 2016 & China & 108 & IBC & HER2-positive & $100 \%$ & IHC & Abcam & IRS score $\geq 7$ & $39.81 \%$ & 32 & EFS, PFS & 9 \\
\hline 5 & $\begin{array}{l}\text { Bhuvaneswari } \\
\text { Ramaswamy }\end{array}$ & 2012 & U.S. & 289 & IBC & NR & NR & $\mathrm{IHC}$ & Sigma & $\geq 10 \%$ & $\begin{array}{l}\text { Epithelial } \\
69 \% \text {, stromal } \\
49 \%\end{array}$ & 96 & OS, DFS & 9 \\
\hline 6 & Yuan $\mathrm{Li}$ & 2012 & China & 262 & $\mathrm{IBC}$ & All & $100 \%$ & $\mathrm{IHC}$ & Santa Cruz & score $\geq 2^{*}$ & $33.59 \%$ & 48.2 & OS, DFS & 7 \\
\hline 7 & Miao $\mathrm{He}$ & 2015 & China & 290 & NR & NR & $100 \%$ & IHC & Abcam & IRS score $\geq 3$ & $54.80 \%$ & NR & OS, DFS & 10 \\
\hline 8 & Haishan Zhao & 2016 & China & 266 & $\begin{array}{l}\text { Invasive ductal } \\
\text { carcinoma/ } \\
\text { invasive lobular } \\
\text { carcinoma }\end{array}$ & NR & $100 \%$ & $\mathrm{IHC}$ & Abcam & IRS score $\geq 3$ & $52.60 \%$ & $48-77$ & OS, DFS & 8 \\
\hline 9 & $\begin{array}{l}\text { Anette ten } \\
\text { Haaf }\end{array}$ & 2009 & Germany & 204 & IBC & NR & $100 \%$ & $\mathrm{IHC}$ & Santa Cruz & IRS score $\geq 7$ & $97 \%$ & 78 & os & 10 \\
\hline 10 & Yinghua Li & 2012 & China & 284 & $\begin{array}{l}\text { ductal and } \\
\text { lobular cancer }\end{array}$ & NR & 100 & $\mathrm{IHC}$ & Santa Cruz & IRS score $\geq 7$ & $83.10 \%$ & 62 & RFS & 9 \\
\hline 11 & Soyoung Im & 2013 & Korea & 334 & IBC & All & 100 & $\mathrm{IHC}$ & Abcam & IRS score $\geq 4$ & $42.20 \%$ & 75.1 & NR & 8 \\
\hline 12 & Yajun Tao & 2011 & China & 83 & $\begin{array}{l}\text { invasive ductal } \\
\text { carcinomas/ } \\
\text { invasive lobular } \\
\text { carcinomas }\end{array}$ & All & NR & IHC & Santa Cruz & NR & NR & NR & NR & 10 \\
\hline 13 & Xin Ge & 2015 & China & 117 & NR & NR & NR & $\mathrm{IHC}$ & Santa Cruz & IRS score $\geq 5$ & NR & NR & NR & 8 \\
\hline
\end{tabular}

NR, not reference; IBC, invasive breast cancers; IHC, immunohistochemistry; IRS, immuno-reactive-score; DFS, disease free survival; OS, overall survival; CSS, cause free survival; EFS, event free survival; RFS, recurrence free survival; DMFS, distant metastasis free survival; NOS, Newcastle-Ottawa Scale.

The nuclear staining intensity: 0 and $3(0=$ negative, $1=$ weak, $2=$ moderate, and $3=$ strong $)$, the percentage of nuclear stained cells: 0 and $4(1 \leq 25 \%, 2=26-50 \%, 3=51-75 \%$, and $4>75 \%)$. IRS was calculated by multiplication of the two scores

*The expressions of Gli1 was scored as intensity of staining: 0 (no staining), 1 (weak/moderate staining) or 2 (intense staining). Gli1 nuclear over-expression was identified for intensity cases with staining intensity of $2+$.

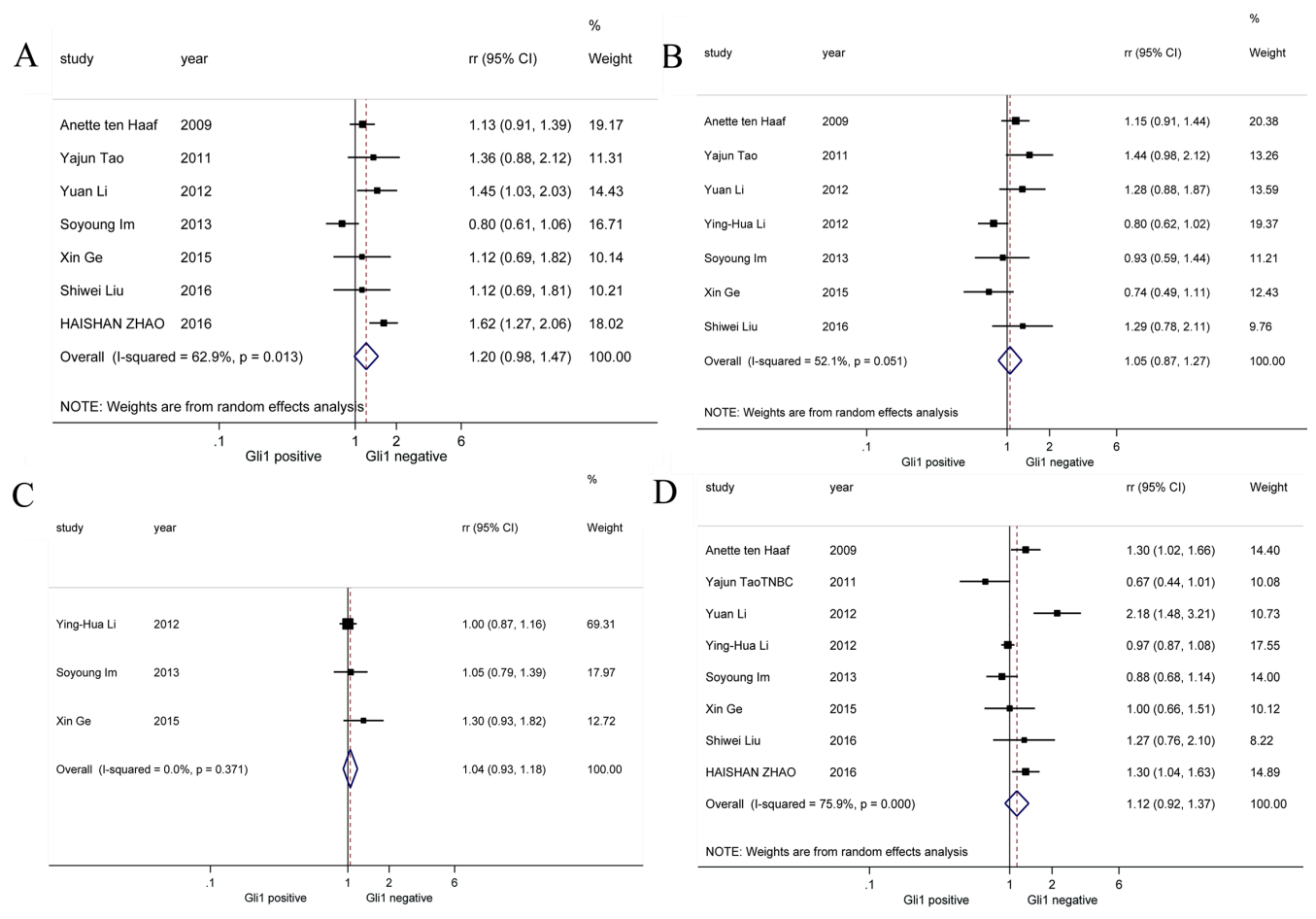

Figure 2: Forrest plots of RRs for correlation between Gli1 over-expression and clinicopathological features. (A) Histological grade, (B) T stage, (C) clinical stage and (D) lymph node metastasis. 
Table 2: Summary of the outcomes presented in this meta-analysis

\begin{tabular}{lllllll}
\hline Group & $\begin{array}{l}\text { No. of } \\
\text { studies }\end{array}$ & $\begin{array}{l}\text { No. of } \\
\text { total patients }\end{array}$ & $\begin{array}{l}\text { RR/HR (95\% CI) } \\
\text { (Gli1 positive VS Gli1 negative) }\end{array}$ & $\begin{array}{l}\boldsymbol{P} \text { for } \\
\text { heterogeneity }\end{array}$ & $\mathbf{I}^{2}$ & references \\
\hline Histological grade & 7 & 1374 & $1.20(0.98,1.47)$ & 0.013 & $62.9 \%$ & {$[19,24,26,28,30-32]$} \\
T stage & 7 & 1309 & $1.05(0.87,1.27)$ & 0.051 & $52.1 \%$ & {$[19,24,26-28,30,32]$} \\
Clinical stage & 3 & 735 & $1.04(0.93,1.18)$ & 0.371 & $0.0 \%$ & {$[24,26,27]$} \\
Lymph node & 8 & 1658 & $1.12(0.92,1.37)$ & 0.000 & $75.9 \%$ & {$[19,24,26-28,30-32]$} \\
metastasis & & 1366 & $1.03(0.74,1.42)$ & 0.000 & $88.0 \%$ & {$[19,26,27,32]$} \\
ER & 5 & $0.92(0.70,1.21)$ & 0.000 & $83.8 \%$ & {$[19,26,27,29,32]$} \\
PR & 4 & 1084 & $1.12(0.90,1.39)$ & 0.106 & $55.4 \%$ & {$[26,27,32]$} \\
Her-2 & 3 & 880 & $1.48(1.14,1.93)$ & 0.038 & $64.5 \%$ & {$[8,25,31,32]$} \\
DFS & 4 & 1107 & $1.74(1.28,2.36)$ & 0.278 & $20.6 \%$ & {$[8,19,25,29,31,32]$} \\
3-year survival & 6 & 1593 & $2.04(1.62,2.57)$ & 0.482 & $0.0 \%$ & {$[8,19,25,29,31,32]$} \\
5-year survival & 6 & 1593 & $2.10(1.64,2.68)$ & 0.961 & $0.0 \%$ & {$[8,19,25,29,31,32]$} \\
OS & 6 & 1593 & &
\end{tabular}

histological grade (Begg: $p=0.881$, Egger: $p=0.994$ ), $\mathrm{T}$ stage (Begg: $p=0.881$, Egger: $p=0.678$ ), clinical stage (Begg: $p=0.117$, Egger: $p=0.350$ ), lymph node metastasis (Begg: $p=1.000$, Egger: $p=0.430$ ), PR (Begg: $p=0.174$, Egger: $p=0.545$ ), ER (Begg: $p=0.624$, Egger: $p=0.998)$, HER-2 (Begg: $p=0.602$, Egger: $p=0.660$ ), DFS (Begg: $p=0.497$, Egger: $p=0.0 .304), 3$-year survival (Begg: $p=0.348$, Egger: $p=0.537$ ), 5-year survival (Begg: $p=0.573$, Egger: $p=0.312$ ) and OS (Begg: $p=0.348$, Egger: $p=0.934$ ).

\section{DISCUSSION}

Gli1 overexpression is revealed to have a close connection with breast cancer as a significant maker of aberrant activation of SHH pathway [33-35]. It involves in the formation and progression of breast cancer in many important ways such as activating tumor associated target genes [36,37], promoting mammary epithelial cell mesenchymal transition (EMT) [38], regulating mammary CSC self-renewal [10] and facilitating angiogenesis [39]. In

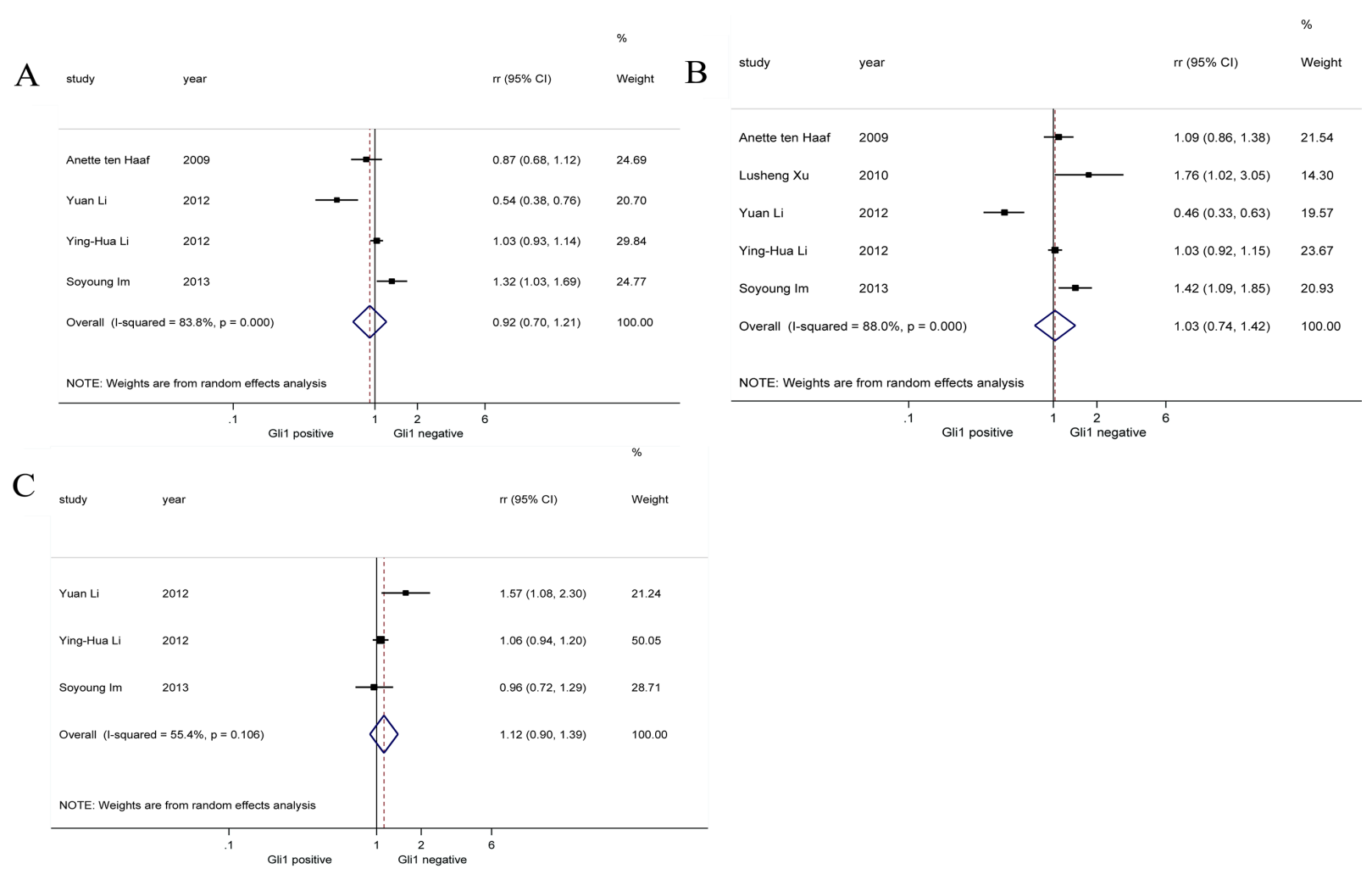

Figure 3: Forrest plots of RRs for correlation between Gli1 over-expression and immunohistochemical parameters in breast cancer. (A) Progesterone receptor (PR), (B) oestrogen receptor (ER), and (C) human epidermal growth factor receptor 2 (HER-2). 


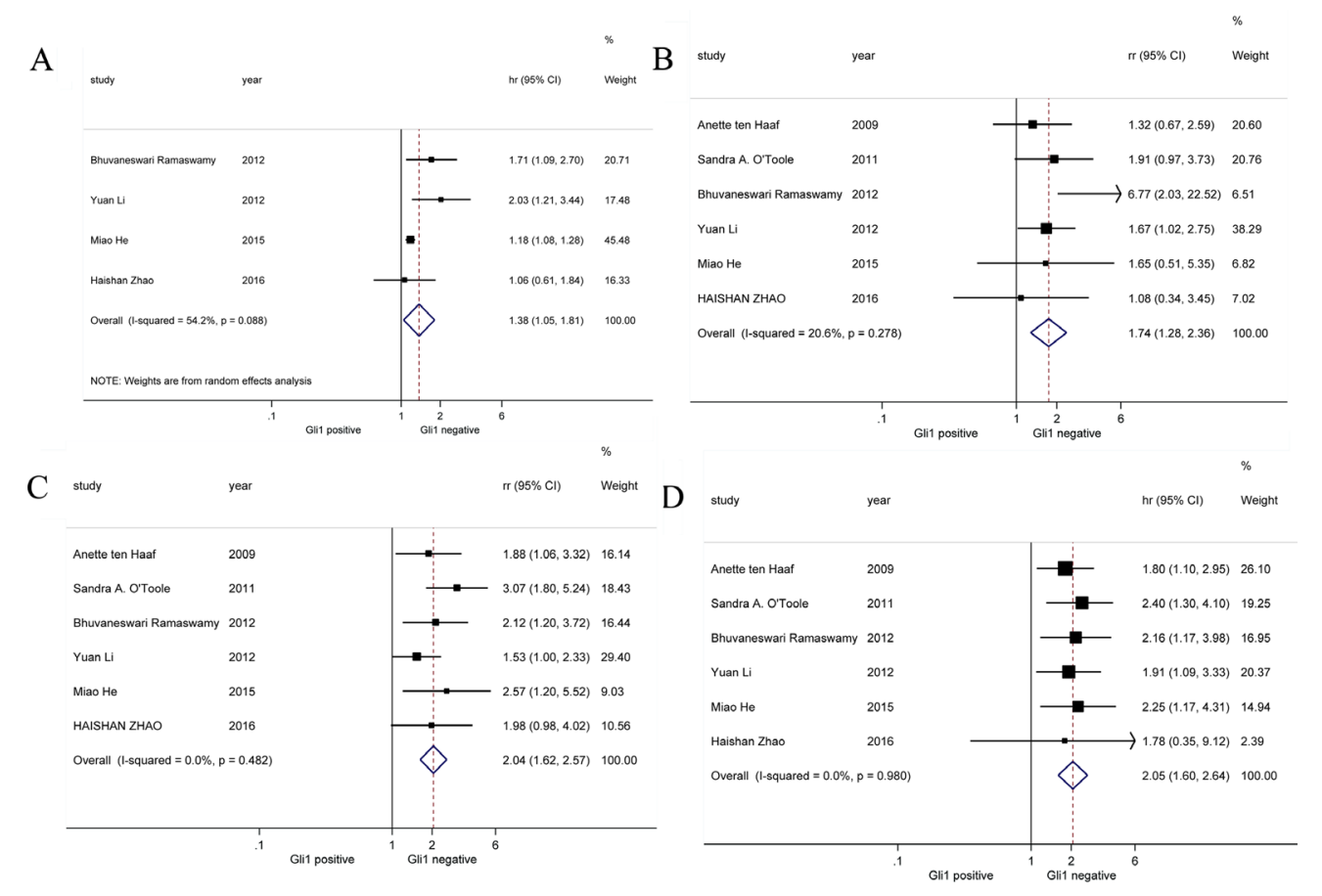

Figure 4: Forrest plots of HR for Gli1 over-expression and the clinical survival outcomes. (A) DFS, (B) 3-year survival, (C) 5-year survival and (D) OS.
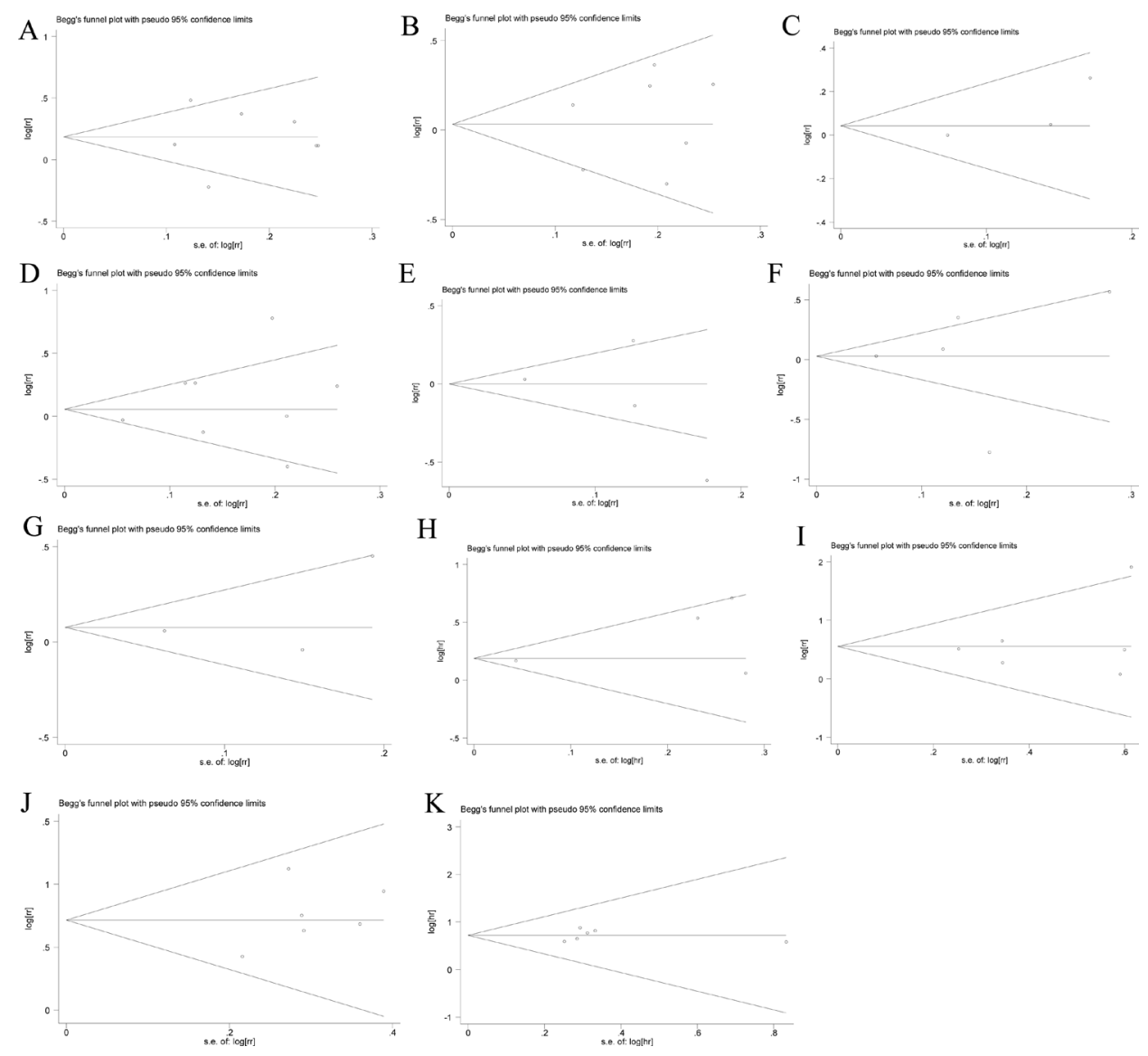

Figure 5: Funnel graph of assessing the potential publication bias of this study. (A) Histological grade, (B) T stage, (C) clinical stage, (D) lymph node metastasis, (E) PR, (F) ER, (G) HER-2, (H) DFS, (I) 3-year survival, (J) 5-year survival and (K) OS. 
addition, researchers have confirmed that inhibiting the Gli1 expression could effectively attenuate tumor growth and migration and indicated its potential role as a therapeutic target in breast cancer management [40, 41]. However, its clinical value as a prognostic marker remains unclear due to differences in detective methods of Glil and selected patients, etc among researches. Therefore we carried out a meta-analysis based on available evidences in order to investigate Gli1 expression with survival and several clinicpathological charactereristics in breast cancer patients.

Our study was the first one to summarize researches of prognostic role of Glil in breast cancer. The result indicated no significant association between Gli1 expression and several clinic-pathological characteristics such as histological grade, T stage, clinical stage and lymph node metastasis. Moreover, we reported PR, ER and HER-2 were not correlated with Gli1 expression in breast cancer. But the relationship between Gli1 over-expression and survival in breast cancer patients might be influenced by the clinicpathological characteristics. Nevertheless, it was remarkable that we confirmed that breast cancer patients with overexpression of Gli1 tended to obtain a worse survival outcome referring to DFS, 3-year survival, 5-year survival and OS.

Diao's study [23] clarified that Gli1 would be a potential therapeutic target, moreover, could also act as a prognostic marker in breast cancer. The research observed that high Gli1 expression was associated with poor distant metastasis free survival (DMFS) in 126 patients $(\mathrm{HR}=4.87,95 \% \mathrm{CI}:[1.34,17.67])$. So the clinical staff should pay more attention to patients with breast cancer with high Gli1 expression in systemic screening, such as increasing the frequency of bone scan. Li's study [27] showed that Glil expression is significantly correlated with aggressive features and unfavorable recurrence free survival (RFS). The breast cancer with nuclear Gli1 overexpression signified early relapse after radical operation, therefore mammary gland color ultrasound is particularly necessary in patient reexamination. Moreover, summarized DFS in our study also supported that the regular rechecks are more necessary in postoperative patients with Glil over expression. What's more, our results reported no significant association between Gli1 expression and hormone receptors expression, which is controversial with Makoto Kubo and Sun reported that Glil expression is positively correlated with ER expression $[42,43]$. Further researches are required to clarify relationship between Gli1 and hormone receptors expression.

There still exist some limitations in our study, which deserve attention. Firstly, definitions of Glil overexpression, detection of subcellular Gli1 localization and antibody source varied in different studies. Secondly, only part of recruited patients has undergone surgery which may contribute to potential bias. Thirdly, for the reason that the number of eligible studies was limited, further detailed analysis of correlation between Gli1 overexpression and clinicopathological features hadn't been carried out. In addition, the heterogeneities across articles cannot be ignored.

Our meta-analysis is the first one to explain Gli1 expression as an aggressive biological behavior in breast cancer patients. It integrated convincing evidence to elucidate relationship between Glil expression and prognosis of breast cancer. The over expression of Gli1 could predict poor survival in patients with breast cancer. Moreover, detection of Gli1 can provid more convincing evidences for guiding the diagnosis and treatment in breast cancer patients.

\section{MATERIALS AND METHODS}

\section{Literature retrieval}

We retrieved articles from PubMed/Medline and EMBASE electronic databases by variablely combining the following terms "Glioma associated oncogene 1", "Gli1", "Hh", "breast cancer", "breast carcinoma". The search ended on 10th March, 2017. Meanwhile, the references for articles and reviews were also screened to identify additional relevant articles. This meta-analysis included publications meeting the following criteria: (1) patients had a diagnosis of breast cancer; (2) expression level of Gli1 were determined with method such as IHC or reverse transcription-polymerase chain reaction (RT-PCR); (3) the studies provided direct hazard ratio (HR) and 95\% confidence interval (CI) for survival or Kaplan-Meier survival curves at different Gli1 expression level; (4) the studies reported Glil expression according to different clinic-pathological parameters of patients. When there is possible duplication of data in several publications, we prefer the most recent or the most integrated study. Studies of letters, case reports, conference abstracts, editorials and reviews without original data; non-English papers; animal or laboratory studies were not in our scope.

\section{Data extraction}

Two investigators reviewed eligible studies to obtain the following information: first author's name, year of publication, source of patients, sample size, mean age of patients, assay method, cut-off definition, TNM stage, histological grade, immunohistochemical features (ER, PR, HER-2), Gli1 expression rate and survival data according to Gli1 expression. Disagreements were discussed by the two investigators and settled by consulting a third author to reach consensus. Moreover, quality assessments of all studies included were conducted by Newcastle-Ottawa-Scale (NOS) criteria. High quality studies refer to those scored 5 or above 5 .

\section{Statistical analysis}

RevMan 5.0 software (Copenhagen, Denmark) was applied to analyze extracted data and calculate RR. To investigate the impact of Gli1 expression on survival 
outcome, HR and 95\% CI from multivariate Cox hazard models were used. If direct data were not available, then Kaplan-Meier survival curves analyses were adopted to yield survival data as what Tierney demonstrated [21]. Further work on association between Gli1 and clinic-pathological characteristics (histological grade, T stage, clinical stage, lymph node metastasis), Gli1 and immunohistochemical parameters (PR, ER, HER-2), Glil and breast cancer survival (DFS, 3-year survival, 5-year survival, OS) were calculated by STATA 12.0 software (Stata Corporation, College Station, TX, USA) and presented in forest plots together with RR or HR and 95\% CI, respectively. For studies with high heterogeneity $\left(I^{2}>50 \%\right)$ or $P<0.10$, random-effects model was utilized for data analysis, otherwise the fixed-effects model was utilized. Publication bias was evaluated by funnel plot with a Begg's test [22]. Asymmetrical distribution of results was estimated to existing publication bias.

\section{Authors' contributions}

Bilan Wang and Lingli Zhang designed the study. Bilan Wang, Ting Yu and Yuzhu Hu wrote the manuscript. Mengmeng Xiang, Haoyu Peng, Yunzhu Lin and Lu Han extracted the relevant studies and data. Yuzhu $\mathrm{Hu}$ and Ting Yu analyzed the data. All authors approved the final edition.

\section{ACKNOWLEDGMENTS AND FUNDING}

This work was supported by the Sichuan University Outstanding Young Scholars Research Fund (2016SCU04A04).

\section{CONFLICTS OF INTEREST}

There is no conflicts of interest to disclose.

\section{REFERENCES}

1. Torre LA, Bray F, Siegel RL, Ferlay J, Lortet-Tieulent J, Jemal A. Global cancer statistics, 2012. CA Cancer J Clin. 2015; 65:87-108.

2. Chen W, Zheng R, Baade PD, Zhang S, Zeng H, Bray F, Jemal A, Yu XQ, He J. Cancer statistics in China, 2015. CA Cancer J Clin. 2016; 66:115-132.

3. Goldhirsch A, Winer EP, Coates AS, Gelber RD, PiccartGebhart M, Thurlimann B, Senn HJ, Panel M. Personalizing the treatment of women with early breast cancer: highlights of the St Gallen International Expert Consensus on the Primary Therapy of Early Breast Cancer 2013. Ann Oncol. 2013; 24:2206-2223.

4. Swain SM, Baselga J, Kim SB, Ro J, Semiglazov V, Campone M, Ciruelos E, Ferrero JM, Schneeweiss A, Heeson S, Clark E, Ross G, Benyunes MC, et al. Pertuzumab, trastuzumab, and docetaxel in HER2-positive metastatic breast cancer. N Engl J Med. 2015; 372:724-734.

5. Bossung V, Harbeck N. Angiogenesis inhibitors in the management of breast cancer. Curr Opin Obstet Gynecol. 2010; 22:79-86.

6. Cardoso F, Costa A, Norton L, Senkus E, Aapro M, Andre F, Barrios CH, Bergh J, Biganzoli L, Blackwell KL, Cardoso MJ, Cufer T, El Saghir N, et al. ESO-ESMO 2nd international consensus guidelines for advanced breast cancer (ABC2). Breast. 2014; 23:489-502.

7. Briscoe J, Therond PP. The mechanisms of Hedgehog signalling and its roles in development and disease. Nat Rev Mol Cell Biol. 2013; 14:416-429.

8. Ramaswamy B, Lu YZ, Teng KY, Nuovo G, Li XB, Shapiro CL, Majumder S. Hedgehog Signaling Is a Novel Therapeutic Target in Tamoxifen-Resistant Breast Cancer Aberrantly Activated by PI3K/AKT Pathway. Cancer Res. 2012; 72:5048-5059.

9. Ingham PW, Nakano Y, Seger C. Mechanisms and functions of Hedgehog signalling across the metazoa. Nat Rev Genet. 2011; 12:393-406.

10. Liu SL, Dontu G, Mantle ID, Patel S, Ahn NS, Jackson KW, Suri $\mathrm{P}$, Wicha MS. Hedgehog signaling and Bmi-1 regulate self-renewal of normal and malignant human mammary stem cells. Cancer Res. 2006; 66:6063-6071.

11. Zhao C, Chen A, Jamieson CH, Fereshteh M, Abrahamsson A, Blum J, Kwon HY, Kim J, Chute JP, Rizzieri D, Munchhof M, VanArsdale T, Beachy PA, et al. Hedgehog signalling is essential for maintenance of cancer stem cells in myeloid leukaemia. Nature. 2009; 458:776-U117.

12. Stecca B, Mas C, Clement V, Zbinden M, Correa R, Piguet V, Beermann F, Ruiz I Altaba A. Melanomas require HEDGEHOG-GLI signaling regulated by interactions between GLI1 and the RAS-MEK/AKT pathways. Proc Natl Acad Sci U S A. 2007; 104:5895-5900.

13. Ruiz i Altaba A. Therapeutic inhibition of Hedgehog-GLI signaling in cancer: epithelial, stromal, or stem cell targets? Cancer cell. 2008; 14:281-283.

14. El-Zaatari M, Tobias A, Grabowska AM, Kumari R, Scotting PJ, Kaye P, Atherton J, Clarke PA, Powe DG, Watson SA. De-regulation of the sonic hedgehog pathway in the InsGas mouse model of gastric carcinogenesis. Br J Cancer. 2007; 96:1855-1861.

15. Karhadkar SS, Bova GS, Abdallah N, Dhara S, Gardner D, Maitra A, Isaacs JT, Berman DM, Beachy PA. Hedgehog signalling in prostate regeneration, neoplasia and metastasis. Nature. 2004; 431:707-712.

16. Watkins DN, Berman DM, Burkholder SG, Wang BL, Beachy PA, Baylin SB. Hedgehog signalling within airway epithelial progenitors and in small-cell lung cancer. Nature. 2003; 422:313-317.

17. Cui Y, Cui CA, Yang ZT, Ni WD, Jin Y, Xuan YH. Gli1 expression in cancer stem-like cells predicts poor prognosis in patients with lung squamous cell carcinoma. Exp Mol Pathol. 2017; 102:347-353. 
18. Chung CH, Dignam JJ, Hammond ME, Klimowicz AC, Petrillo SK, Magliocco A, Jordan R, Trotti A, Spencer S, Cooper JS, Le QT, Ang KK. Glioma-associated oncogene family zinc finger 1 expression and metastasis in patients with head and neck squamous cell carcinoma treated with radiation therapy (RTOG 9003). J Clin Oncol. 2011; 29:1326-1334.

19. ten Haaf A, Bektas N, von Serenyi S, Losen I, Arweiler EC, Hartmann A, Knuchel R, Dahl E. Expression of the gliomaassociated oncogene homolog (GLI) 1 in human breast cancer is associated with unfavourable overall survival. BMC cancer. 2009; 9.

20. $\mathrm{Xu} \mathrm{LS}$, Kwon YJ, Frolova N, Steg AD, Yuan K, Johnson MR, Grizzle WE, Desmond RA, Frost AR. Gli1 promotes cell survival and is predictive of a poor outcome in ER alpha-negative breast cancer. Breast Cancer Res Treat. 2010; 123:59-71.

21. Tierney JF, Stewart LA, Ghersi D, Burdett S, Sydes MR. Practical methods for incorporating summary time-to-event data into meta-analysis. Trials. 2007; 8.

22. Begg CB, Mazumdar M. Operating characteristics of a rank correlation test for publication bias. Biometrics. 1994; 50:1088-1101.

23. Diao Y, Azatyan A, Rahman MF, Zhao C, Zhu J, DahlmanWright K, Zaphiropoulos PG. Blockade of the Hedgehog pathway downregulates estrogen receptor alpha signaling in breast cancer cells. Oncotarget. 2016; 7:71580-71593. https://doi.org/10.18632/oncotarget.12259.

24. Ge X, Lyu P, Gu Y, Li L, Li J, Wang Y, Zhang L, Fu C, Cao Z. Sonic hedgehog stimulates glycolysis and proliferation of breast cancer cells: Modulation of PFKFB3 activation. Biochem Biophys Res Commun. 2015; 464:862-868.

25. He M, Fu Y, Yan Y, Xiao Q, Wu H, Yao W, Zhao H, Zhao L, Jiang Q, Yu Z, Jin F, Mi X, Wang E, et al. The Hedgehog signalling pathway mediates drug response of $\mathrm{MCF}-7$ mammosphere cells in breast cancer patients. Clin Sci (Lond). 2015; 129:809-822.

26. Im S, Choi HJ, Yoo C, Jung JH, Jeon YW, Suh YJ, Kang CS. Hedgehog Related Protein Expression in Breast Cancer: Gli-2 Is Associated with Poor Overall Survival. Korean J Pathol. 2013; 47:116-123.

27. Li YH, Gao HF, Wang Y, Liu F, Tian XF, Zhang Y. Overexpression of Gli1 in cancer interstitial tissues predicts early relapse after radical operation of breast cancer. Chin J Cancer Res. 2012; 24:263-274.

28. Liu SW, Duan XN, Xu L, Ye JM, Cheng YJ, Liu Q, Zhang H, Zhang S, Zhu SA, Li T, Liu YH. Nuclear Gli1 expression is associated with pathological complete response and event-free survival in HER2-positive breast cancer treated with trastuzumab-based neoadjuvant therapy. Tumour Biol. 2016; 37:4873-4881.

29. O'Toole SA, Machalek DA, Shearer RF, Millar EKA, Nair R, Schofield P, McLeod D, Cooper CL, McNeil CM, McFarland A, Nguyen A, Ormandy CJ, Qiu MR, et al.
Hedgehog Overexpression Is Associated with Stromal Interactions and Predicts for Poor Outcome in Breast Cancer. Cancer Res. 2011; 71:4002-4014.

30. Tao YJ, Mao J, Zhang QQ, Li LH. Overexpression of Hedgehog signaling molecules and its involvement in triple-negative breast cancer. Oncol Lett. 2011; 2:995-1001.

31. Zhao HS, Tang HT, Xiao QH, He M, Zhao L, Fu YZ, Wu HZ, Yu ZJ, Jiang Q, Yan YY, Jin F, Wei MJ. The Hedgehog signaling pathway is associated with poor prognosis in breast cancer patients with the CD44(+)/ CD24(-) phenotype. Mol Med Rep. 2016; 14:5261-5270.

32. Li Y, Yang WT, Yang Q, Zhou S. Nuclear localization of GLI1 and elevated expression of FOXC2 in breast cancer is associated with the basal-like phenotype. Histol Histopathol. 2012; 27:475-484.

33. Nessling M, Richter K, Schwaenen C, Roerig P, Wrobel G, Wessendorf S, Fritz B, Bentz M, Sinn HP, Radlwimmer B, Lichter P. Candidate genes in breast cancer revealed by microarray-based comparative genomic hybridization of archived tissue. Cancer Res. 2005; 65:439-447.

34. Mukherjee S, Frolova N, Sadlonova A, Novak Z, Steg A, Page GP, Welch DR, Lobo-Ruppert SM, Ruppert JM, Johnson MR, Frost AR. Hedgehog signaling and response to cyclopamine differ in epithelial and stromal cells in benign breast and breast cancer. Cancer Biol Ther. 2006; 5:674-683.

35. Lu L, Wu ML, Zhao FX, Fu WH, Li WD, Li X, Liu T. Prognostic and clinicopathological value of Gli-1 expression in gastric cancer: A meta-analysis. Oncotarget. 2016; 7:69087-69096. https://doi.org/10.18632/oncotarget.12011.

36. Lee J, Platt KA, Censullo P, Ruiz i Altaba A. Gli1 is a target of Sonic hedgehog that induces ventral neural tube development. Development. 1997; 124:2537-2552.

37. Kasper M, Regi G, Frischauf AM, Aberger F. GLI transcription factors: Mediators of oncogenic Hedgehog signalling. Eur J Cancer. 2006; 42:437-445.

38. Fiaschi M, Rozell B, Bergstrom A, Toftgard R, Kleman MI. Targeted expression of GLI1 in the mammary gland disrupts pregnancy-induced maturation and causes lactation failure. J Biol Chem. 2007; 282:36090-36101.

39. Harris LG, Pannell LK, Singh S, Samant RS, Shevde LA. Increased vascularity and spontaneous metastasis of breast cancer by hedgehog signaling mediated upregulation of cyr61. Oncogene. 2012; 31:3370-3380.

40. Benvenuto M, Masuelli L, De Smaele E, Fantini M, Mattera R, Cucchi D, Bonanno E, Di Stefano E, Frajese GV, Orlandi A, Screpanti I, Gulino A, Modesti A, et al. In vitro and in vivo inhibition of breast cancer cell growth by targeting the Hedgehog/GLI pathway with SMO (GDC-0449) or GLI (GANT-61) inhibitors. Oncotarget. 2016; 7:9250-9270. https://doi.org/10.18632/oncotarget.7062.

41. Thomas ZI, Gibson W, Sexton JZ, Aird KM, Ingram SM, Aldrich A, Lyerly HK, Devi GR, Williams KP. Targeting GLI1 expression in human inflammatory breast cancer cells 
enhances apoptosis and attenuates migration. Br J Cancer. 2011; 104:1575-1586.

42. Sun Y, Wang YS, Fan C, Gao P, Wang XW, Wei GW, Wei JM. Estrogen promotes stemness and invasiveness of ER-positive breast cancer cells through Glil activation. Mol Cancer. 2014; 13.
43. Kubo M, Nakamura M, Tasaki A, Yamanaka N, Nakashima H, Nomura M, Kuroki S, Katano M. Hedgehog signaling pathway is a new therapeutic target for patients with breast cancer. Cancer Res. 2004; 64:6071-6074. 